\title{
Discourse Strategies for Global Topic Construction in Complex Written Texts: Evidence from Comment Articles
}

\author{
Pilar Alonso \\ University of Salamanca \\ alonso@usal.es
}

\begin{abstract}
Based on research done on a small corpus of comment articles, this paper reconsiders the relation between topic entity, subject function and given status and explores their role in the construction and maintenance of the global discourse topic. It claims that even though it is pertinent to say that at sentence level much of the topical information is non-subject and/or frequently postverbal with new informational status, at discourse level the progression established between non-subjects and subject elements ends up converting topical non-subjects into subjects. In the long term, this means that using subject position frequency as a primary variable in determining possible candidates to global discourse topic is significant and relevant. The article shows that the conversion of topical non-subjects into subjects is done not only by means of lexical recurrence and reference, as Givón (1990) claims; but also by other means such as extended reference, anticipatory it, general nouns or superordinates and complex clausal structures. This is illustrated with evidence from a selection of comment articles from The Observer, The Times and The Guardian.
\end{abstract}

\section{Introduction}

In his seminal work, Syntax: A Functional-Typological Introduction, Givón (1990) devotes a chapter to "the grammar of referential coherence" and claims that "grammar-in-text methodology has been indispensable in helping us to elucidate a number of rough-and- 
ready notions of discourse function" (1990: 893). Central among those elements of discourse structure which grammar helps to define and identify, Givón mentions the notion of discourse topic. Unlike those researchers who tend to consider topic "a clause level function" in opposition to the notion of comment (cf. Dahl, 1974; Reinhart, 1982; Gundel, 1974/1989), Givón considers that topic is "a relevant functional notion only at the discourse level, minimally at the chain or paragraph level", and claims that "coherent discourse is [...] characterized by equi-topic clause-chains". Furthermore, for Givón, "coherence across a multi-clause chain means continuity ('recurrence') of the sub-elements of coherence, chief among which are the referents/topics". Thus Givón considers that "the topic is only 'talked about' or 'important' if it remains 'talked about' or 'important' during a number of successive clauses" (1990: 902). This is broadly the position that serves as the point of departure for the present analysis where some of the linguistic devices which support the construction and maintenance of complex global topics at discourse level are studied. We address this issue by exploring the types of semantic chains which are built up from the intersentential / interpropositional relations established among topics at clause level. Based on the analysis of a small corpus of media articles, we will show that topical semantic units are progressively developed throughout discourse not only by means of lexical recurrence and co-referential items, as Givón observes; there are other cohesive devices drawing from various grammatical resources, such as demonstrative deictic reference, extended reference, subject extraposition and complex syntactic constructions, which are used to recover and project local information onto global topicality. What is more, we will see how these resources consistently tend to restructure the grammatical status of those informational items occurring in non-subject position to subject position, which becomes extremely useful for the systematic identification and analysis of global discourse topic candidates on a frequency/hierarchy criterion (Givón, 1990; Alonso, 1995, 1999, 2005).

\section{Some theoretical considerations}

Before examining our illustration of global topic construction in media articles, it should be said that the notion of topic is far from being clear-cut in current linguistic research, the main difficulty arising not only from the technical complexity involved in topic identification (given the numerous candidates that may satisfy the conditions set out for this semantic role), but also from its coexistence with other related notions which are used in the literature to refer to similar or complementary functions. Depending on the theoretical approach chosen, the notion of topic is usually found in combination with the semantic notion of comment (Hockett, 1958; Dahl, 1974; van Dijk, 1977, 1985; Gundel, 1974/1989; Reinhart, 1982; van Dijk and Kintsch, 1983; Werth, 1984; Chafe, 1994), both of which pose an alternative to the quasi-equivalent concepts of theme and rheme preferred in the European linguistic tradition (Petöfi and Söcer, 1983; Halliday, 1985; Downing and Locke, 1992; Downing, 2000, 2001; de Beaugrande, 1997), not to mention the interplay 
between these notions and other related concepts such as focus, ground, left-dislocation, etc.

Although there are significant differences among researchers regarding the syntactic, semantic, or informational status of the terms topic and comment (Gundel, 1999: 6), there is a very broad consensus that these terms refer to the partition of the information contained in a sentence, with the topic addressing its "aboutness" (Gundel, 1974/1989; Reinhart, 1982; Gregory and Michaelis, 2001), and the comment the progression or advance of the information at clause level. In short, and as Gundel (1999: 13) points out, in the clausal topic-comment structure there is a semantic conceptual representation of the information determined by the grammar which presents the topic as "what the sentence is about" and the comment as "the main predication about the topic". However, this sense of "aboutness" is not necessarily restricted to semantic and/or grammatical conditions, for it is usually made to refer to the producer's actions or intentions in the selection and formulation of topics. The interaction between the organization of the information and the participants' decisions is already present in a rudimentary way in Hockett's classical definition of clausal topic:

The most general characteristic of predicative constructions is suggested by the terms 'topic' and 'comment' for their ICs [immediate constituents]: the speaker announces a topic and then says something about it (1958: 201).

Gundel expands this definition of topic to include fundamental components in communication; she describes topic as what "the speaker intends to increase the addressee's knowledge about, request information about, or otherwise get the addressee to act with respect to" (1988: 210). In both cases, the emphasis is put on the speaker or writer as creator or activator of topics; the same criterion is used by Brown and Yule at discourse level, when they describe the notion of topic as "what is being talked about" (1983:71) and "insist on the principle that it is speakers and writers who have topics, not texts" (1983:68). Identifying topics in a sentence or discourse string requires, however, adopting some decisions regarding their grammatical distribution and/or their informational status. Based on the quantified study of the topicality of grammatical subjects, Givon (1990: 900-901) contends that "human language seems to code grammatically only three discourse levels of topicality of the participants in events/states", which are:

(a) Main topic $=$ subject

(b) Secondary topic $=$ direct object

(c) Non-topic $=$ all other roles

Out of these options he considers the subject "consistently more topical than the direct object", thus constraining the initial assumption, namely that "if the topical participants in the clause are its nominal arguments (subjects, objects), then at first glance the clause may have a whole host of topics" (1990: 901). This position also seems to contradict those theories, which, attending mainly to questions of information highlighting, consider 
fronting, left-dislocation, thematization or focusing as topic marking or topic promoting constructions and, therefore, tend to interpret sentences with fronted elements as multiple topic sentences (cf. for example, Gregory and Michaelis, 2001; Jaeger and Oshima, 2002). The issue could be resolved if the question of "aboutness", which is typical of fronted elements, were separated from the condition of being "activated", "in focus" or "prominent" (Gundel, 1999: 5). Brown and Yule opt for this approach when they formally and functionally dissociate left-dislocation or fronting from content-topics. Their proposal is innovative in the sense that it involves combining and distinguishing between the functions of two terms which are traditionally considered parallel: theme and topic. At sentential/propositional level, Brown and Yule identify "theme" with "the left-most constituent of the sentence" regardless of its syntactic class or informational load. By doing so, they assign it only one of the multiple functions which Halliday and his collaborators (cf. Halliday and Hasan, 1976: 325; Halliday, 1985: 38-64) attribute to the term, i.e. that which refers to "what the speakers/writers use as... point of departure" (Brown and Yule, 1983: 127). As for topic, Brown and Yule describe the notion as "what is being talked about" (1983: 71), which is in agreement with the majority of the literature. The interesting point about the Brown and Yule distinction between the functions of theme and topic concerns precisely the fact that focalization and aboutness become independent issues in the sentence structure, as topics may or may not be "thematized", depending on the degree of markedness associated with the chosen topic entity (aboutness $+/$ - point of departure and enhancement) (cf. Alonso, 2005). The consequence is that fronted elements with syntactic roles which are not first-rank candidates for topic entity (e.g. adverbials) may be considered salient elements in the sentential structure (involving intentional choice on the part of the producer who selects them as point of departure for his/her utterance), but they do not necessarily end up being what is talked about in the sentence, especially in the case of what Halliday calls "simple marked themes" (cf. Halliday, 1985: 45-48).

But if the question of topic recognition is up to a certain point solved at the grammatical level by Givón's proposal that clausal topics "are more likely to be coded grammatically as the clause's subject or direct object" (1990: 900), at the information level a connection must also be made between the semantic role of these syntactic constituents, which are central for the organization of the propositional contents of a clause, and the informational status allotted to them. In their formulation of the given-new contract, which is meant to describe the working agreement between speaker and hearer in the comprehension process, Clark and Haviland (1977) relate the syntactic distribution of sentential patterns to the two types of information which are conveyed in communication: given (i.e., information (supposedly or presented as) known or recoverable by the receiver from the previous text or from general/shared world knowledge of some type) and new (i.e., information (supposedly or presented as) novel to the receiver). They contend that, in simple standard English sentences with normal intonation and focal stress, the tendency is for given to come before new (1977:13), a principle assumed to be followed by participants in the communication process. 
The information structure of sentences, texts and discourse has often proved useful to investigate the notion of topichood, its syntactic and semantic realization and its textual or discourse development and projection (cf. Halliday and Hasan, 1976; Halliday, 1985; Chafe, 1994; Gundel, 1999; Gregory and Michaelis, 2001; to cite just a few). In her classic proposal of a taxonomy of given-new information, Prince (1981) studies, among many other factors, the intersection between the informational terms given/new and their syntactic and semantic functions. First, she distinguishes between three types of givenness which are not necessarily independent from one another or mutually exclusive: predictability, saliency, and shared knowledge (of linguistic, textual or contextual phenomena) and terms their combination "assumed familiarity". Second, she discusses these interactive realizations of givenness in the information structure of the sentence and the corresponding sentence position assumed by producers and receivers (1981: 233). Evidence from the clausal analysis of an informal oral text points at the grammaticalinformational correspondence between subject/given non-subject/new ("one-sixth of the non-subjects - but none of the subjects - are New" (1981:242)), a fact that, in view of the previous discussion, could help characterize the clausal topic as preferably occurring in subject position and informatively presented as given or known. But the situation encountered in the analysis of a theoretical written text (the beginning of a chapter in Hymes' Foundations in Sociolinguistics) shows that this correspondence is not so easy to establish at least at surface level. Prince enumerates and examines the differences between the analyses of the two texts; we will merely draw attention to three of the aspects she mentions: the abstractedness of many of the entities; their size and complexity; and the blurred correlation between given/new status and grammatical subject position (with reference to the analysis of the Hymes text Prince says: "no Brand-new entities occur at all, but a few Unused ones do, in subject as well as nonsubject position" (1981:252)). All three of the problems identified by Prince have been corroborated by the findings we obtained from the qualitative and quantitative analysis of a small corpus of comment articles from The Guardian, The Observer and The Times which are being analysed as part of an ongoing research project on coherence in media discourse. Our analysis of the data has shown, however, that complex written discourse employs specific strategies to convert highly intricate new-information chunks occurring at sentence level in non-subject topical position into topical/given/subject entities as the text progresses. Thus, at discourse level topical informational units of global projection and relevance (in subject or non-subject position) end up integrated into a semantic informational intersentential chain realised and developed by subsequent sentential subjects semantically interrelated through lexical reiteration, reference and other grammatically-based cohesive devices. These recurrent and/or emergent grammatical subjects, which, even if they cannot be considered topical at the local sentential level, facilitate the conversion of information previously presented as new into given, are key elements in the construction and maintenance of discourse topicality or "aboutness". Based on this fact we claim that, from an overall perspective, a correlation may be established between the notions of grammatical subject, informational given status and semantic topic. This is in agreement with Givón (1990: 896-897), who considers 
recurrence one of the backbones of discourse coherence and processing; furthermore, our findings complement his approach by identifying other resources which help to recover previous complex information for the topical, subject and given functions at discourse level.

\section{Discourse strategies for global topic construction}

\subsection{Lexico-referential resources}

In previous works (cf. Alonso, 1999, 2005), we used the above correlation: recurrent topic entity / subject position / given status, as an index for the description of topical discourse construction and progression. We focused on the macrostructural recovering and reusage of sentential information which occurs at discourse level (Danes, 1974; Petöfi and Sözer, 1983; Givón, 1990; Chafe, 1994; Downing, 2001), and showed how cohesive resources such as co-reference and lexical reiteration (in all the subtypes described by Halliday and Hasan (1976) and Halliday (1985), i.e., repetition, synonym, superordinate, hyponym or meronym, and general word) served to construct global discourse topics. We demonstrated that these cohesive resources achieved this either by sustaining sentential topical entities in subject position and given status, or by converting sentential topical entities in non-subject position and with new informational status into topical entities occurring as subjects and presented as given in subsequent sentences. An example of this straightforward procedure based on a high-frequency criterion is the analysis of the following text (cf. Alonso, 2005: 143-144). Here recurrence of sentential subjects has been measured to evaluate their potentiality as prospective discourse topics (sentential subjects appear in bold type; when they occupy thematic initial position they have also been italicized):

(1) Finland and Iceland are Nordic but not Scandinavian.(1) Scandinavia comprises only Sweden, Denmark and Norway.(2)

While it has many social values in common, Finland has several marked points of difference with its Nordic neighbours and partners. (3) For a start the Finnish language is not Germanic but in a class of its own.(4) Theoretically it belongs in the same language group as Hungarian, but for practical purposes the two are mutually incomprehensible.(5) Finnish is the first language for about 94 per cent of the population, Swedish for 6 per cent.(6) Both are official languages. (7) Statistically the fifth largest country in Europe, a third of Finland lies above the Artic circle and is not much use to anyone.(8) Helsinki is the northernmost capital in the European Union.(9) The population is 5 million, of whom about a million live in the capital, the only city of any size.(10) The two next biggest towns, Tampere and Turku, have about 200,000 inhabitants(11).

The analysis of the frequency of appearance of the different sentential topics in this text and the assessment of the semantic relations holding them together (Halliday and Hasan, 1976; Halliday, 1985) gives evidence of the central role that recurrence of sententially topicalized 
entities with subject function and given status plays in the construction of the global topic of discourse. At the local level, and giving each sentential topic the number assigned to their respective sentences above, we have the following:

T1 Finland and Iceland

T2 Scandinavia (superordinate of T1)

T3 Finland (partial repetition of $\mathrm{T} 1, \mathrm{~T} 2$; hierarchically more prominent in $\mathrm{T} 1$ according to linearity)

T4 The Finnish language (meronym of T1)

$\mathrm{T} 5$ it (in reference to $\mathrm{T} 4$ )

T6 Finnish (repetition of T4)

T7 Both (reference to T4 and Swedish, in this order)

T8 A third of Finland (combination of reference and repetition of T1)

T9 Helsinki (meronym of T1)

T10 The population (meronym of $\mathrm{T} 1$ )

T11 The two next biggest towns (combination of reference and superordination of T9, and meronym of $\mathrm{T} 1$ )

The visual consideration of the elements which are found in sentential topic position in the text shows an array of candidates for the position of discourse topic. The semantic analysis indicates, however, that the more recurrent topic (either directly or through some type of lexical reiteration, namely superordination, meronymy, or co-reference, as indicated in brackets following each case) is the first element encountered in T1 (i.e. Finland). This is reinforced by the fact that it occupies discourse thematic position (i.e. the point of departure chosen by the producer to start his text) and that, with no exception, all other sentential topics are presented as hierarchically subordinate to it. This is the case, for example, of the highly recurrent "Finnish" (4 occurrences), which occupies the middle position in the sentential topic chain, or "Iceland" whose non-prominence at discourse level can easily be supported by the frequency/hierarchy criteria. First, its role as topic is merely local, as its appearance in sentence (1) is its only occurrence in the whole discourse; second, even if it actually shares discourse thematic prominence with the discourse topic (i.e. Finland) in (1), the second position it occupies at phrasal level makes it hierarchically less prominent. From this perspective and for a very general description of what is being talked about in this text (topic as aboutness), it would probably suffice to mention that the topic of the discourse is "Finland".

The analysis of a reduced but varied corpus of written texts in English (cf. Alonso, $1995 ; 1999 ; 2005)$ has shown that there is an internal mechanism in the progression of discourse topic construction which is directly linked to the recurrence of entities in subject position and with given informational status. This lexico-referential topical progression is rather simple to trace in easy-to-follow texts such as the one above, and has indeed been found in some of the comment articles in our corpus. For example, the article "I'll always be Daddy's girl at heart" (Viv Groskop, Observer, June 19, 2005) presents a highly regular case of topicality based on recurrence of semantically-related sentential subjects. The 
article consists of thirty-five sentences, in seven of them $(2,3,4,9,10,14,15)$ the entity functioning as grammatical subject is directly or indirectly related with "the relationship between fathers and daughters", which appears in the first sentence of the text ("There is something rather odd about the fact that the relationship between fathers and daughters is never celebrated - or even rarely mentioned", my italics). Thus, in the sentences mentioned above we have:

(2) The Electra Complex (hyponym: specific type of relation, or meronym: aspects of the father/daughter relationship)

(3) The only well known paean to the father daughter relationship (partial repetition in italics)

(4) The da-da-da (meronym for Marilyn Monroe's 'My Heart Belongs to Daddy' in sentence 3)

(9) fathers and daughters (partial repetition)

(10) The relationship between a male parent and a girl child (repetition)

(14) The relationship between daddy and daughter / they (repetition / personal reference)

(15) This [type of relationship] (anaphoric demonstrative deictic reference)

Moreover, a more specific version of the same topic, related to the macrostructural title of the article, "the relationship between my father and I" practically occupies all subject positions (seventeen out of nineteen sentences) in the second half of the article, either in the combination "my father and I" (sentences 17, 32) or as separate entities: "I" (sentences 18, 21 to 31 and 33) and "He" $(19,34)$. As can be appreciated, heavy use is made now of referential items ( $\mathrm{I} / \mathrm{he}$ ) to progress in the construction of the central discourse topic. Other sub-topics of the discourse with a substantially lower frequency range are "the relationship between mothers and daughters" (sentences $5,6,16$ ); "the relationship between fathers and sons" (sentences 7,8); and other local topics (sentences 11, 12,13) related to Elisabeth Gaskell, whose work Wives and Daughters is used to illustrate the writer's point.

\subsection{Other referential and grammatical resources}

The progressive development and construction of the discourse topic may become more intricate, as Halliday remarks (1985: 315), in other more involved types of texts such as argumentative comment articles. In these cases, the tendency continues to be for all or part of the non-subject/new topical information to become subject/given in subsequent sentences, thus entering and sustaining the dynamic pattern described above according to which the high-frequency subject position is a determining factor in the construction and identification of the global discourse topic. However, when the density of the new nonsubject topical information that has to be recovered for reusage as given topic makes recourse to lexical items totally insufficient, discourse employs other resources which involve both cohesive devices and syntactic structures. In the corpus of media articles analysed, we have been able to identify the regular consistent use of a series of linguistic strategies which facilitate the transition of complex information from post-verbal to preverbal position. Some of them could be considered different instantiations of what Halliday and Hasan (1976: 52-53) call "extended reference", a mechanism which makes it possible 
to recover and reuse large stretches of text (complex phrases, sentences, paragraphs, or longer portions). Halliday and Hasan mention as paradigmatic types of extended reference realization the use of personal $i t$ and deictic demonstratives this and that. We have found numerous examples of both in our corpus, as can be seen in the following selections, where both resources are presented in bold type (all other clausal subjects are in italics):

(2) Very few people who are canvassed on the matter will admit to working just for the money. Even jobs with no purpose at all outside the generation of money (trading), or jobs in which no mental engagement is required (modelling) - even these spawn talk of challenge, of adrenaline, creativity, art, as if there were no greater shame than to work purely for cash, to "sell yourself". Indeed, so called "celebrity culture", before it even filters into the creation of unrealistic expectations, has the effect of merging the person with the job; the source of the fame is indivisible from the fame itself and the fame indivisible from the person.

So, the highest state of attainment is one in which every aspect of one's self is expressed in the work that one does. It's nothing more than a late-capitalist lie, perpetuated with the crude intent of making people believe that, if they're unhappy in their work, if their work undervalues or exploits or even just bores them, it's their own fault for not being valuable enough to warrant a more interesting job. (Zoe Williams, "Born into tedium" (The Guardian, 23-11-2004).

(3) Being a Muslim, especially a Muslim woman, in Britain is for many a dispiriting and occasionally terrifying experience. The society that prides itself on tolerance has lost its bearings over Islam. On the streets, the prejudice that Islam is irrationally and murderously violent and menacingly foreign has spawned a subculture of hatred and abuse. If you are a woman in a hijab, being jeered at, even spat at, is routine. Many never venture from their houses.

This is fertile ground for widespread racism and where the law is currently uncertain. (Will Hutton, "A gagging order too far" (The Observer, 19-6-2005).

(4) Any explanation about the way European civilisation overtook the Islamic world and China, both of which were more advanced until at least the 13th and 14th centuries, and, in China's case later still, has to incorporate the capacity of Europe to accept the intellectual and practical consequences of the catalytic impact of ideas. Continuing technological innovation drove growth; but behind technological innovation lay the Enlightenment's willingness, which did not exist elsewhere, to subject every belief and tradition to sceptical inquiry and to accept the practical consequences. This is part of any conceptualisation of modernity; it is at the core of who we are and it is profoundly secular and sometimes abusive about the way religion may hold back human advances. (Will Hutton, "A gagging order too far" (The Observer, 19-6-2005).

We have italicized information in subject position in all clauses to show that however topical it is, there are, within the boundaries of the sentence and as part of its comment structure, other pieces of information which are also essential for global topicality. In all 
cases, these chunks of highly complex information, regardless of their syntactic function or informational status, are progressively incorporated into the discourse flow as subject/topic/given information by means of the cohesive referential items "it" (in example 2) and "this" (in example 3). These items serve to recover the totality of the information in previous portions of text, and in fact example 4 actually shows how both "this" and "it" in combination perform this function. This evidence brings a new approach to Givón's claim that the role of deictic demonstratives in the referential accessibility of topics in connected discourse is pragmatic and linked to the shared speech situation (1990: 903). The use of referential "it" and deictic demonstratives as instantiators of extended text reference gives them a cotextual semantic dimension central for integrating given and new information of a complex type into the topic of discourse with the minimum processing requirements. Our research thus shows that deictic demonstratives play an essential intersentential and intratextual role in the construction of topical coherence, for they help both to construct and to establish the discourse topic as well as to maintain discourse continuity.

This use of personal referential items and demonstrative deictics is just one of the possible strategies that discourse employs to promote local information to global topic prominence. A similar function of complex information recovering is played by superordinate and general words to which Halliday and Hasan (1976: 274-282) attribute a strong referential capacity. Here superordinates or general words do not stand in a relation of reiteration of previous lexical items as is typical of their function in lexical cohesion, but they are in a way parallel to extended reference resources which operate to recover semantic information chunks. In the following passage (where clausal subjects have again been italicized), there is actually a combination of resources: demonstrative deictic "this"; superordinate "burden-sharing"; and general word "evidence" (in bold type). All of these features serve to reuse previous complex information:

(5) But the most dramatic increase has been in fathers' involvement - from taking on 13 per cent of childcare in 1961 to 33 per cent today. This has allowed women to go out to work with a clearer conscience and to recuperate a little at weekends. Burden-sharing makes bringing up children so much less frazzling.

All the evidence shows, too, that this is good for the children. Those whose fathers are actively involved in caring for them do better at school, are less likely to fall into crime, form closer relationships in adulthood and are less likely to suffer mental illness. (Mary Ann Sieghart "Happily, every day is Fathers' Day for more families now" (The Times, 16-62005).

However, as can be seen in the second paragraph of example 5 with the word "evidence", the function of reference elements or general words is not only anaphoric (i.e., limited to integrating previous complex information into the discourse), they can also be used cataphorically to anticipate complex noun clauses or phrases. This provides a way to indirectly project topical prominence onto the subject slot despite the post-verbal position 
of the informational unit. This is a typical function of dummy "it" when it is used as extraposed subject, as in the following cases:

(6) It is a matter of concern to me as a British citizen that this degree of inequality exists in my country; it is of wider concern that Islam predisposes its adherents to poverty, backwardness and sexism because it incubates deep resentment and, at its extremes, terrorism. (Will Hutton, "A gagging order too far" (The Observer, 19-6-2005).

A similar combination of resources is found in the following excerpt where essential topical information is recovered and reused in later portions of the text and converted into topical subject/given information regardless of the position they occupied in their preceding occurrences. Here, it is done by using referential "it", a superordinate or general word like "[further] action" and a combination of both reference and superordination as "its" and "bill" in the phrase "its [Defra's] proposed bill" (all cases have been highlighted in bold type and, for clarity, all sentences have been numbered):

(7) With law and order at the top of the agenda in the Queen's speech yesterday, it is no surprise that antisocial behaviour also merited several mentions.(1) It's a clear public priority on which the government wants to prove its tough credentials.(2) Despite a raft of new powers being introduced in the last few years, the government is keen to add to the armoury of measures available to those on the frontline to tackle problems of nuisance, harassment, intimidation and general 'yobbishness'.(3)

But the latest promise of further action comes not from the Home Office, but rather from the Department for the Environment, Food and Rural Affairs (Defra). (4) Its proposed bill sets out the extension of powers for councils to use on-the-spot fines for litter, fly-tipping, abandoned vehicles, fly-posting and night-time noise nuisance.(5)

It is part of a wider drive towards increasing the powers of local authorities and police to take control of crime and antisocial behaviour in communities and neighbourhoods.(6)

(Laura Edwards, "Local authority". The Guardian, 24-11-2004).

Thus, in this excerpt, there are several instances of interest to our point:

1. The use of referential dummy "it" in sentence (1) which strategically occupies topical/subject/given position in cataphoric anticipation of the information contained in the extraposed subject nominal clause that follows ("that antisocial behaviour also merited several mentions");

2. the referential "it" in sentence (2) which in the preceding sentence recovers both topical and thematic information (in the sense given here to theme as left-most constituent or point of departure);

3. the superordinate or general word "action" in sentence (4), which serves to convert previous post-verbal information (such as "add to the armoury of measures available to those on the frontline to tackle problems of nuisance, harassment, intimidation and general 'yobbishness'" in sentence (3)) into topical given information in subject position; 
4. The association in the phrase "its proposed bill" of possessive "its" (with reference to "Defra" in post-verbal position in the previous sentence) and "proposed bill" in (5) (acting as quasi synonym or hyponym of "further action" above), which produces what we could denominate a semantically complex topic as it is the result of a combination of a number of already elaborated topics (as has been seen in the description of "action" above).

5. The use of "It" in (6) as extended reference to recover all complex information from the extensive description covered in the previous portion of text and convert it once more into a topic entity with subject function and given status.

Finally, we wish to mention yet another strategy that has been repeatedly found in our reduced corpus of comment articles: not only is local topical post-verbal new information converted into given topics with subject function but the new information is also combined with and integrated into different topics of variable complexity and status. This is achieved by using syntactically complex subjects which have the capacity to integrate different pieces of information into one single syntactic structure, as happens in the example below where different elements from previously given information (here italicised) are recovered, combined and compacted in order to form a complex subject construction (here highlighted in bold type; sentences have been numbered for easier reference):

(8) The new measures are accused by some of being draconian. (1) Certainly, we must interrogate how the powers are implemented to ensure they are used justly and proportionately.(2) This does not always happen; new powers, such as Asbos, are sometimes used inconsistently and inappropriately.(3)

It is crucial too that they are not used to fast track juvenile offenders towards custody we need to reduce rather than increase the prison population.(4) Ensuring the accountability of those using the new powers to the communities they serve is vital.(5) New powers must be matched by a commitment to clear democratic mechanisms of accountability to ensure that they are used fairly.(6)

(Laura Edwards, "Local authority". The Guardian, 24-11-2004).

The passage also shows instances (in sentences 3 and 4 respectively and in bold type) of demonstrative deictic "this" with the role of complex information reusage as topic in subject position, and dummy "it" occupying subject position for the extraposed topical nominal clause, as well as instances of lexical reiteration (e.g. new powers in sentence 6 , also highlighted). This demonstrates that the resources described above are very common and highly productive.

\section{Conclusion}

Our research has shown that there is a difference between the processes of identification and recognition of topics depending on whether they are operating within a local or a global scope. These findings concur with those of previous studies, some of which have been discussed above, and it may be argued that at the local sentential level topic position is not 
fixed and it is even possible to affirm that there may be more than one topic in a sentence. In this sense and at this level of analysis, we should assume therefore that there is no automatic correspondence between the notion of topic entity on the one hand, and that of subject function and given status on the other. When the structure of discourse is analysed, however, a different pattern of behaviour has been observed and it becomes a consistent feature that essential information sustained throughout the entire discourse ends up occupying subject position with a certain (often high) degree of recurrence, thus agreeing with what Givón (1990) claims. We have shown that in simple texts recurrence tends to be either referential or lexical, involving in the latter case not merely exact repetition of the same word but also other instances of reiteration such as synonyms, superordinates, hyponyms, meronyms or general words, to use Halliday's terms. When it comes to complex texts, our research has demonstrated that there are other resources which help to (1) recover complex topical information from previous sentences (in subject or non-subject position) and (2) anticipate large pieces of information in post-verbal position. These complex chunks of information, which serve to reuse single stretches of topical information or to combine several topical entities and/or portions of information from preceding sentences, are then assigned subject function and given status. In this fashion, they enter the string of semantically related topical entities with subject function and given status which is progressively built over the entire length of the discourse. The resources used to achieve this effect are, as has been seen, referential it, demonstrative deictics, anticipatory it, lexical superordinates and general words, and finally complex phrases or clauses. In this sense, we are in a position to state that at the global discourse level a high frequency rate in the occurrence of a topic entity in subject position and with given status is significant and may be used as a strong indicator of discourse topicality.

\section{References}

Alonso, Pilar (1995): "Summary writing and summary evaluation: A method based on semantic discourse analysis". Revista Complutense de Estudios Ingleses, Núm. 3: 151-171.

. (1999): "Claves para la comprensión y el aprendizaje del concepto de coherencia discursiva”. Cuadernos de Investigación Filológica, Tomo XXV: 39-52.

. (2002): "The macrostructural function of recurrence in complex narrative discourse". In. P. Alonso, M.J. Sánchez, J. Hyde \& C. Moran eds., Aspects of Discourse Analysis. Salamanca: Ediciones Universidad de Salamanca, 45-77.

. (2005): Semantics. A Discourse Perspective. Oviedo: Septem Ediciones.

Beaugrande, Robert de (1997): New Foundations for a Science of Text and Discourse. Norwood: Ablex.

Brown, Gillian and George Yule (1983): Discourse Analysis. Cambridge: Cambridge University Press.

Chafe, Wallace (1994): Discourse, Consciousness and Time. Chicago: The University of Chicago Press.

Clark, Herbert and Susan Haviland (1977): "Comprehension and the given-new contract". In R.O. Freedle, ed., Discourse Production and Comprehension. Norwood: Ablex, 1-40. 
Dahl, Osten (ed.) (1974): Topic and Comment, Contextual Boundness and Focus. Hamburg: Buske.

Danes, Frantisek (1974): "Functional sentence perspective and the organization of the text". In F. Danes, ed., Papers on Functional Sentence Perspective. Prague: Academia, 106-128.

Downing, Angela (2000): "Talking Topically". clac 3/2000. U. Complutense de Madrid.

[http://www.ucm.es/info/circulo/no3/downing.htm].

. (2001): "Thematic Progression as a Functional Resource in Analysing Texts". clac $5 / 2001$. Universidad Complutense de Madrid.

[http://www.ucm.es/info/circulo/no5/downing.htm].

Downing, Angela and Philip Locke (1992): A University Course in English Grammar. New York: Prentice Hall.

Francis, Hartwell, Michelle Gregory and Laura Michaelis (1999): "Morphosyntactic reflexes of a marked referential choice: lexical subjects in conversational English". Proceedings of the Chicago Linguistic Society 35: 85-97.

[ http://www.acsu.buffalo.edu/ mgregory/papers/clslex.pdf].

Gregory, Michelle and Laura Michaelis (2001): "Topicalization and left-dislocation: A functional opposition revisited". Journal of Pragmatics 33: 1665-1706.

Gundel, Jeanette (1974/1989): The Role of Topic and Comment in Linguistic Theory. New York: Garland.

(1988): "Universals of topic-comment structure". In M. Hammond, E. Moravcsik and

J. Wirth, eds., Studies in Syntactic Typology. Amsterdam: John Benjamins, 209-239.

. (1999): "Topic, focus, and the grammar-pragmatic interface". In J. Alexander, N. Han and M. Minnick Fox, eds., Proceedings of the $23^{\text {rd }}$. Annual Penn Linguistics Colloquium.

U. Penn Working Papers in Linguistics. Vol. 6.1.

[ http://www.ling.upenn.edu/papers/v6.1-contents.html].

Halliday, M.A.K. (1985): An Introduction to Functional Grammar. London: Arnold

Halliday, M.A.K. and Ruqaiya Hasan (1976): Cohesion in English. London: Longman.

Hockett, Charles F. (1958): A Course in Modern Linguistics. New York: Macmillan.

Jaeger, Florian and David Oshima (2002): "Towards a dynamic model of topic marking". Stanford

Semantics and Pragmatics Workshop: The Construction of Meaning. Stanford Humanities

Center and the Mellon Foundation.

[http://www-linguistics.stanford.edu/semgroup/archive/2002/autumn.html].

Petöfi, János and Emel Sözer (eds.) (1983): Micro and Macro Connexity of Texts. Hamburg:

Helmut Buske.

Prince, Ellen (1981): "Toward a taxonomy of given-new information". In P. Cole, ed., Radical Pragmatics. Pages. New York: Academic Press, 223-255.

Reinhart, Tanja (1982): Pragmatics and Linguistics: An Analysis of Sentence Topics. Bloomington:

Indiana University Linguistics Club.

van Dijk, Teun A. (1977): Text and Context. Explorations in the Semantics and Pragmatics of Discourse. London: Longman.

. (1985): "Semantic Discourse Analysis". In T.A. van Dijk, ed., Handbook of Discourse Analysis Vol.2. London: Academic Press, 103-136.

van Dijk, T. A. and Walter Kintch (1983): Strategies of Discourse Comprehension. New York: Academic Press.

Werth, Paul (1984): Focus, Coherence and Emphasis. London: Croom Helm. 